\title{
Influence of Mechanical Strain on the Electrochemical Lithiation of Aluminum-Based Electrode Materials
}

\section{$\operatorname{AUTHOR(S):~}$}

Ichitsubo, Tetsu; Yagi, Shunsuke; Doi, Takayuki; Yukitani, Shunsuke; Hirai, Kosuke; Matsubara, Eiichiro

\section{CITATION:}

Ichitsubo, Tetsu ...[et al]. Influence of Mechanical Strain on the Electrochemical Lithiation of Aluminum-Based Electrode Materials. Journal of The Electrochemical Society 2011, 159(1): A14-A17

\section{ISSUE DATE:}

2011-12

URL:

http://hdl.handle.net/2433/154863

RIGHT:

(C) 2012 The Electrochemical Society. 


\title{
Influence of Mechanical Strain on the Electrochemical Lithiation of Aluminum-Based Electrode Materials
}

\author{
Tetsu Ichitsubo, ${ }^{\mathrm{a}, \mathrm{z}}$ Shunsuke Yagi, ${ }^{\mathrm{b}, *}$ Takayuki Doi, ${ }^{\mathrm{c}, *}$ Shunsuke Yukitani, ${ }^{\mathrm{a}}$ \\ Kosuke Hirai, ${ }^{a}$ and Eiichiro Matsubara ${ }^{a}$ \\ ${ }^{a}$ Department of Materials Science and Engineering, Kyoto University, Kyoto 606-8501, Japan \\ ${ }^{b}$ Nanoscience and Nanotechnology Research Center, Osaka Prefecture University, Osaka 599-8570, Japan \\ ${ }^{c}$ Office of Society-Academia Collaboration for Innovation, Kyoto University, Kyoto 615-8520, Japan
}

\begin{abstract}
While an Al-Li alloy is expected to be useful as an active material for a negative electrode in a Li battery, the electrochemical lithiation of pure $\mathrm{Al}$ metal is known to be quite difficult. In this work, we sought to clarify why an $\mathrm{Al}$ electrode hardly absorbs $\mathrm{Li}$ from a pure Al state, from the viewpoint of elasticity theory and thermodynamics. We consider two cases: (i) an AlLi compound with elastic strain due to volume expansion is formed in the $\mathrm{Al}$ matrix, and (ii) $\mathrm{Li}$ ions are absorbed into an $\mathrm{Al}$ electrode that has been pre-strained by rolling. These strain-energy effects are discussed with the aid of a chemical-potential diagram and the Gibbs-Duhem equation.
\end{abstract}

(C) 2011 The Electrochemical Society. [DOI: 10.1149/2.038201jes] All rights reserved.

Manuscript submitted May 26, 2011; revised manuscript received October 7, 2011. Published December 8, 2011.

Lithium-ion batteries (LIB) or lithium batteries (LB) are currently under extensive investigation for the future development of electric vehicles and the establishment of energy-storage systems for use with solar power generation. To achieve these goals, we require a battery system with a large capacity and high cycle performance, in addition to a high cell voltage and high current density. To enhance the capacity of LIB or LB, alternative positive and negative electrodes have been studied. ${ }^{1,2} \mathrm{Al}, \mathrm{Sn}$, their alloys and composites are expected to be useful as high-capacity negative-electrode materials. ${ }^{3-12} \mathrm{Al}$ and $\mathrm{Sn}$ form several kinds of $\mathrm{Li}$ compounds with theoretical capacities (994 $\mathrm{mAh} / \mathrm{g}$ for both of AlLi and $\mathrm{Sn}_{5} \mathrm{Li}_{22}$ ) that greatly exceed that of carbon $(372 \mathrm{mAh} / \mathrm{g})$, where the capacities are evaluated per $1 \mathrm{~g}$ of $\mathrm{Sn}$, $\mathrm{Al}$ and $\mathrm{C}$. However, even though they are excellent materials in terms of capacity, they usually show poor cycle performance; i.e., there is a trade-off between capacity and cycle performance. This is because $\mathrm{Li}$ ions infiltrate the negative-electrode material accompanied by the formation of Li compounds with high molar volumes, and, as a result, the elastic-strain energy dominates the phase equilibrium and kinetics of the lithiation and delithiation processes.

Recently, the effects of elastic strain that accompanies lithiation have received much attention with respect to the cell voltage and phase transition, ${ }^{13-16}$ because the strain-stress effect has been recognized as a fundamental issue to be considered in an intercalation battery system. We previously reported the strain-energy effects on the Sn electrode potential in LBs, ${ }^{13,14}$ and showed that such mechanical strain causes the following fundamental phenomena: (i) the electrode potential tends to be lower than the value predicted by considering only chemical thermodynamics, (ii) the kinetics of lithiation/delithiation are significantly retarded, and (iii) the electromotive force, emf, can be controlled by using the elastic strain.

There is an important difference between the Sn-Li system and the Al-Li system: in the former, $\mathrm{Sn}-28.6$ at\% $\mathrm{Li}\left(\mathrm{Sn}_{5} \mathrm{Li}_{2}\right)$ has the lowest Li composition, while in the latter, Al-50at\%Li (AlLi) has the lowest Li composition. The change in molar volume $\Omega$ (per 1 mole of the host element) is much greater for $\mathrm{Al}\left(\Omega_{\mathrm{AlLi}} / \Omega_{\mathrm{Al}}=1.95\right)$ than for Sn $\left(\Omega_{\mathrm{Sn}_{5} \mathrm{Li}_{2}} / \Omega_{\mathrm{Sn}}=1.22\right)$. Thus, the elastic strain can have a much greater effect on the transformation in the Al-Li system. In this study, by considering the strain energy when an AlLi compound is formed in the $\mathrm{Al}$ matrix (in terms of the phase diagram, $\mathrm{Al}$ and $\mathrm{AlLi}$ are in twophase equilibrium), we demonstrate why $\mathrm{Li}$ ions are hardly absorbed into the $\mathrm{Al}$ matrix. The strain effect is shown to have an important influence on the electrode reaction and its kinetics. In addition, we consider the case in which the $\mathrm{Al}$ electrode stores strain energy (as

\footnotetext{
* Electrochemical Society Active Member.

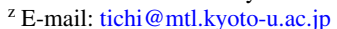

mechanical work) from the outset. The effects of strain-energy are discussed with the aid of a chemical potential diagram and the GibbsDuhem equation.

\section{Experimental}

We prepared two-electrode $\mathrm{Li} / \mathrm{Al}$ cells, in which $\mathrm{Al}$ metal was used as a positive electrode and $\mathrm{Li}$ was a negative electrode with an electrolyte, $1 \mathrm{M} \mathrm{LiPF}_{6}$ in a solution of $33 \%$ ethylene carbonate and $67 \%$ dimethyl carbonate. All of the cells were assembled in an argon-filled glove box and all experiments were performed at room temperature. In the present experiments, we used a Battery Labo System (Keisokuki Center Corporation, Japan) for charge-discharge tests, and the current density was $0.025 \mathrm{~mA} / \mathrm{cm}^{2}$. The bulk Al used here was typically plate-like, about $10 \mathrm{~mm}$ square and about $180 \mu \mathrm{m}$ thick. The purity of $\mathrm{Al}$ was 99.2 wt. \% (Fe: $0.51, \mathrm{Si}: 0.12, \mathrm{Cu}: 0.11$, Mn: 0.01, Mg: 0.01, Zn: 0.01, Ti: 0.04 in wt. \%).

We performed two types of experiments with different $\mathrm{Al}$ electrodes: a non-strained Al electrode and a previously strained electrode. Several kinds of strained Al plates $(31,54$ and $76 \%$ rolled) were prepared by rolling (rolled samples were provided by Prof. N. Tsuji and Dr. D. Terada, Kyoto University).

\section{Calculation of Strain Energy}

The elastic-strain energy that accompanied Li-compound formation in the lithiation process was evaluated through the use of micromechanics theory. ${ }^{17,18}$ Here, an isolated spherical inclusion of the Al-Li compound is assumed to be formed in an elastically isotropic Al matrix. The elastic strain is given by $\epsilon(\mathbf{x})=\gamma(\mathbf{x})-\epsilon^{*}(\mathbf{x})$, where $\gamma$ and $\epsilon^{*}$ are the total strain and eigenstrain, respectively, at a position $\mathbf{x}$. $\epsilon^{*}$ represents an average eigenstrain determined for the volume containing 1 mole of $\mathrm{Al}$ atoms in the $\mathrm{Li}-\mathrm{Al}$ compound, the components of which can be given by $\epsilon_{i j}^{*}=\left(\sqrt[3]{\Omega_{\mathrm{I}} / \Omega_{\mathrm{M}}}-1\right) \delta_{i j} \equiv \epsilon^{*} \delta_{i j}$, where $\delta_{i j}$ is the Kronecker delta, $\Omega$ denotes the volume of each phase including 1 mole of $\mathrm{Al}$ atoms (hereafter referred to as the molar volume), and the subscripts "M" and "I" denote the matrix and inclusion, respectively. When the spherical inclusion has a constant eigenstrain, $\epsilon^{*}$, the elastic-strain energy $U_{\mathrm{s}}$ of the system that includes an isolated inclusion with molar volume $\Omega$ is given by

$$
\begin{gathered}
U_{\mathrm{s}}=\frac{1}{2} \int_{\mathrm{D}} \sigma_{i j}(\mathbf{x}) \epsilon_{i j}(\mathbf{x}) d \mathbf{x}=-\frac{1}{2} B\left(S_{\mathrm{I}}+2 S_{\mathrm{II}}-1\right) \epsilon_{\mathrm{v}}^{* 2} \Omega \\
S_{\mathrm{I}}=\frac{7-5 \nu}{15(1-\nu)}, \quad S_{\mathrm{II}}=-\frac{1-5 \nu}{15(1-\nu)},
\end{gathered}
$$

where $\sigma_{i j}$ is the internal stress, $\epsilon_{\mathrm{v}}^{*}=3 \epsilon^{*}, B$ is the bulk modulus, $\nu$ is Poisson's ratio of the matrix, and $S_{\mathrm{I}}$ and $S_{\mathrm{II}}$ are the Eshelby tensors. ${ }^{17,18}$ 
Based on the literature, ${ }^{19}$ we used values of $B=75.9 \mathrm{GPa}, \nu=0.345$, $\epsilon^{*}=0.249$, and $\Omega=10.0 \times 10^{-6} \mathrm{~m}^{3} / \mathrm{mol}$ for the calculation.

When an isolated inclusion of the AlLi compound is formed in the $\mathrm{Al}$ matrix, the $\mathrm{Al}$ matrix itself is also strained and stores the elastic strain energy as well as AlLi. Thus, the stored elastic strain energy consists mainly of that in the AlLi inclusion and also of that in the $\mathrm{Al}$ matrix. However, the $\mathrm{Al}$ matrix can be assumed to be infinite in comparison to the infinitesimal AlLi inclusion, so that only the AlLi inclusion is considered to be responsible for the elastic-strain energy stored in the whole system. Namely, the chemical potential of the Al matrix remains unchanged, while the chemical potential of $\mathrm{Li}$ in the AlLi inclusion is changed due to the elastic strain energy.

\section{Results and Discussion}

Figure 1a shows the voltage versus capacity in the initial stage of lithiation at a low current density of $0.025 \mathrm{~mA} / \mathrm{cm}^{2}$. The initial high voltage (at about $0.8 \mathrm{~V}$ ) is probably due to oxides in the $\mathrm{Al}$ matrix (although the oxidized surface was polished in the Ar glove box). Interestingly, the minimum voltage then appears and the voltage increases slightly and remains almost constant at about $0.25 \mathrm{~V}$, which is in good agreement (including the IR drop) with the potential in the formation of an AlLi compound. ${ }^{20}$ Figure $1 \mathrm{~b}$ shows the open circuit voltage $(\mathrm{OCV})$ versus the rest time (RT). The $\mathrm{OCV}$ values recover (or increase) with the rest time despite the open circuit condition, indicating that the internal structure of the electrode material changes with RT. For a graphite negative electrode, the OCV value frequently increases by self-discharge which causes decomposition of the electrolyte (i.e., formation of an SEI), which is usually observed in the
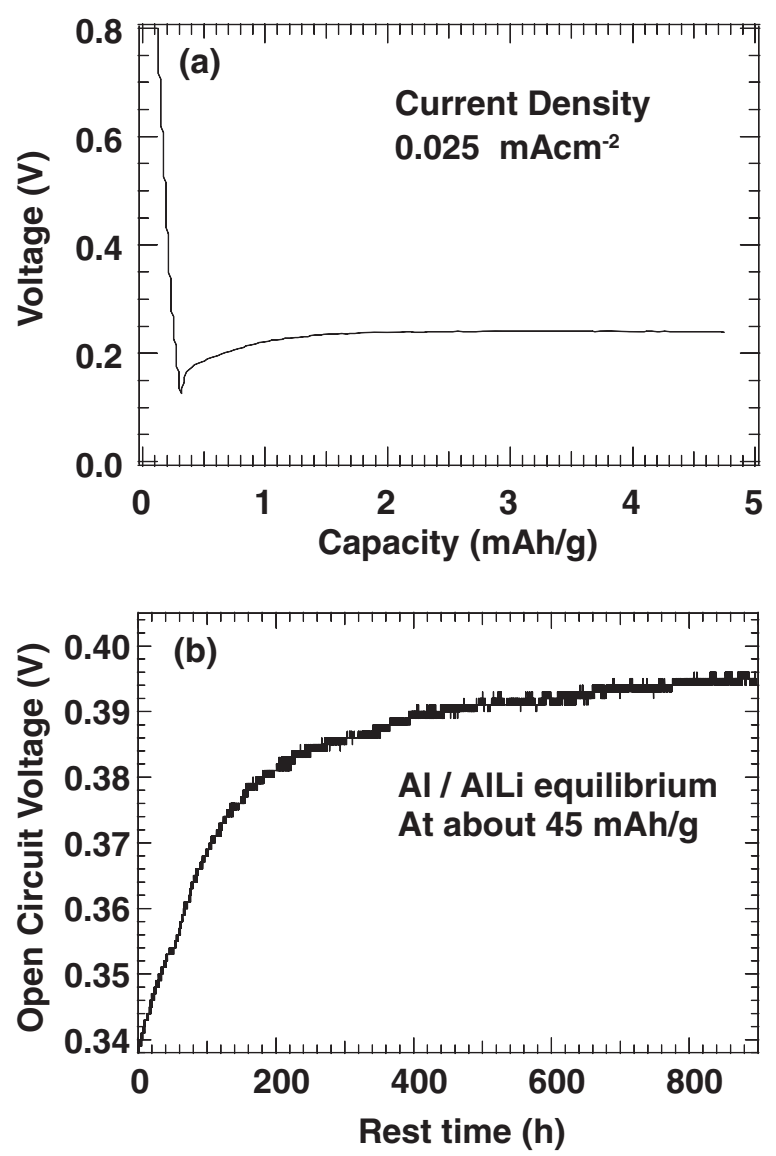

Figure 1. (a) Cell voltage-capacity curves at a constant current of $0.025 \mathrm{~mA} / \mathrm{cm}^{2}$ in the initial stage of lithiation. (b) OCV versus RT curves in Al/AlLi equilibrium. Equilibration was not achieved even after a rest time of up to $800 \mathrm{~h}$.

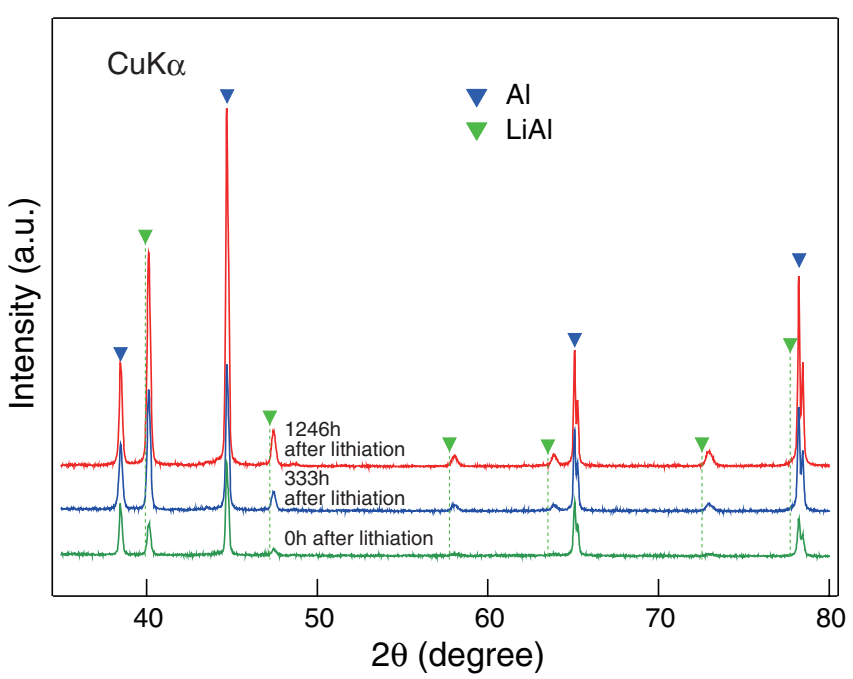

Figure 2. Time-dependence of X-ray diffraction profiles (just after, $333 \mathrm{~h}$, $1246 \mathrm{~h}$ ) after lithiation (less than $50 \mathrm{at} \% \mathrm{Li}$ ).

single-phase reaction. In the Al-Li system, AlLi and Al matrix exist in a two-phase equilibrium, so that even if $\mathrm{Li}$ ions are desorbed from AlLi into the electrolyte by self-discharge, the OCV should remain constant. Therefore, this increase in OCV in Fig. 1b is not due to self-discharge, but rather is considered to be due to accommodation (partial creep and destruction) of the $\mathrm{Al}$ matrix through release of the large transformation strain of AlLi (namely, the strain energy stored in AlLi is released due to the accomodation of the $\mathrm{Al}$ matrix); this is discussed below. Although equilibrium is not achieved, despite the long rest time (about $800 \mathrm{~h}$ ), the OCV value seems to be substantially consistent with the values predicted from previous experiments performed at high temperature. ${ }^{9,10}$

Figure 2 shows the $\mathrm{X}$-ray diffraction profiles versus rest time after some amount of lithiation. The amount of lithiation is an arbitrary large value (less than 50at\% Li) so that we can detect visible AlLi diffraction peaks in the X-ray diffraction measurement, not corresponding to Fig. 1 in the initial lithiation stage. The diffraction peaks of AlLi after lithiation are located at higher angles than those in the standard data from the powder diffraction file for the AlLi compound, which indicates that the AlLi compound is contracted in the Al matrix. The volume elastic strain is roughly estimated to be about $1.2 \%$ from the peak shift, which gives a hydrostatic pressure of about $1 \mathrm{GPa}$. This pressure is fairly large, but as seen in a later calculation, most of the elastic strain due to volume expansion caused by lithiation is actually considered to be released by creep deformation of the $\mathrm{Al}$ matrix in this case. Furthermore, despite the rest time, the peak intensities of AlLi increase with an increase in the rest time after lithiation, which implies that Li-rich regions (not compound) are formed during lithiation (which may also cause the decrease in the electrode potential), since, with regard to the strain energy, it is difficult for AlLi to be formed in the Al matrix. Thus, formation of the AlLi compound is significantly retarded under the elastically constraint.

Figure 3 shows OCV versus RT for various strained $\mathrm{Al}$ electrodes. Obviously, the OCV values for rolled electrodes tend to be higher than that for the non-strained $\mathrm{Al}$ electrode. Since the OCV values were not equilibrated within the present rest time, we cannot discuss the difference between the absolute values of the respective OCVs. However, we can identify a qualitative tendency that strained $\mathrm{Al}$ electrodes with higher reduction show higher OCV. The OCV recovery rate also increases for a higher roll-reduction electrode. This is probably because the rolled $\mathrm{Al}$ electrodes become brittle so that the elastic strain can be released relatively easily.

Here, we try to understand the effects of strain-energy on the lithiation reaction more intuitively and more scientifically. In the discharge 


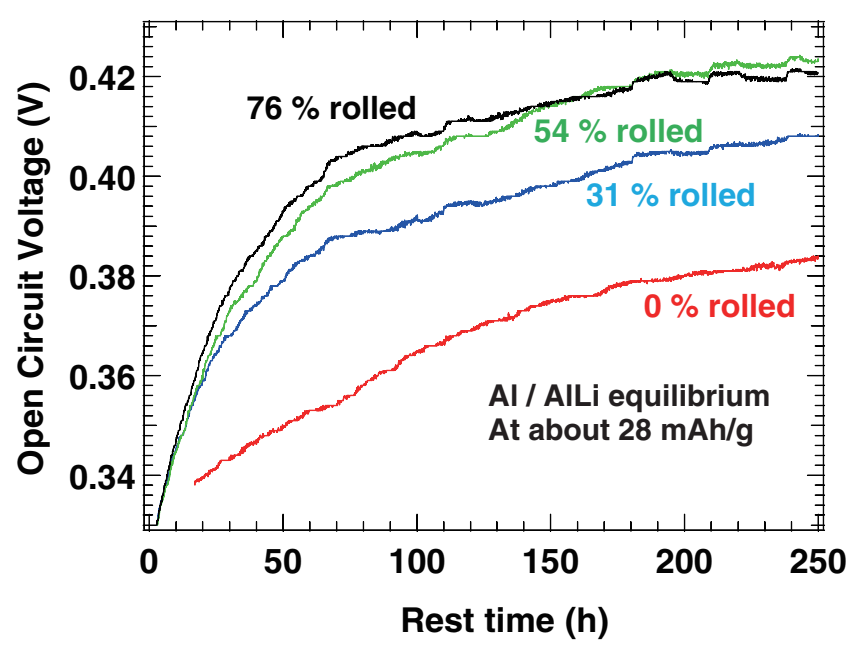

Figure 3. OCV versus rest-time curves for several kinds of rolled Al electrodes in dual phases of $\mathrm{Al}$ and $\mathrm{AlLi}$.

process, the anodic and cathodic reactions are as follows:

$$
\text { Anode }: \mathrm{Li}=\mathrm{Li}^{+}+\mathrm{e}^{-} \text {, }
$$

$$
\text { Cathode : } \mathrm{Al}^{\mathrm{n}, \mathrm{s}}+\mathrm{Li}^{+}+\mathrm{e}^{-}=\mathrm{AlLi}_{\text {in }} \mathrm{Al}^{\mathrm{n}, \mathrm{s}},
$$

$$
\text { Total : } \mathrm{Al}^{\mathrm{n}, \mathrm{s}}+\mathrm{Li}=\mathrm{AlLi} \text { in } \mathrm{Al}^{\mathrm{n}, \mathrm{s}},
$$

where $\mathrm{Al}^{\mathrm{n}}$ and $\mathrm{Al}^{\mathrm{s}}$ refer to non-strained $\mathrm{Al}$ and strained $\mathrm{Al}$, respectively. Since the AlLi compound is to be formed in the Al matrix, it is denoted as $\mathrm{AlLi}$ in $\mathrm{A}^{\mathrm{n}, \mathrm{s}}$ in these reactions. The measurement was performed at room temperature, and therefore $\mathrm{Al}$ was in the solid state and elastically hard. Thus, AlLi with an increasing volume is to be formed in the Al matrix under elastic constraint. Figure 4 shows the chemical potential diagram to explain the change in the electrode potential for various cases. Fundamentally, the electrode potential (or OCV for a two-electrode cell with a $\mathrm{Li}$ negative electrode) of $\mathrm{Li}$ ion batteries is given by the change in the chemical potential of $\mathrm{Li}$ between the positive and negative electrodes (Al/AlLi and Li, respectively, in this case). If $\mathrm{AlLi}$ is assumed to be formed without any strain, the Li chemical potential is $\mu_{\mathrm{Li}}^{\mathrm{n}}$ in Fig. $4 \mathrm{a}$. Let $\Delta G_{\text {chem }}$ $(<0)$ be the Gibbs free energy of AlLi formation (per 1 mole of Al) in Eq. (5). Then, $\Delta G_{\text {chem }}=\left(\mu_{\mathrm{Li}}^{\mathrm{n}}+\mu_{\mathrm{Al}}\right)-\left(\mu_{\mathrm{Li}}^{0}+\mu_{\mathrm{Al}}^{0}\right)=\mu_{\mathrm{Li}}^{\mathrm{n}}-\mu_{\mathrm{Li}}^{0}$, since $\mu_{\mathrm{Al}}=\mu_{\mathrm{Al}}^{0}$ when AlLi is in equilibrium with pure Al. Hence, $e m f^{\mathrm{n}}$ vs $\mathrm{Li}^{2} / \mathrm{Li}^{+}$can be expressed as

$$
e m f^{\mathrm{n}}=-\frac{\mu_{\mathrm{Li}}^{\mathrm{n}}-\mu_{\mathrm{Li}}^{0}}{F}=-\frac{\Delta G_{\text {chem }}}{F},
$$

where $F$ is the Faraday constant. In contrast, when the formed AlLi stores the strain energy $U_{\mathrm{s}}$ (per 1 mole of $\mathrm{Al}$ ), the change in chemical potential in Li, $\Delta \mu_{\mathrm{Li}} \equiv \mu_{\mathrm{Li}}^{\mathrm{s}}-\mu_{\mathrm{Li}}^{\mathrm{n}}$, equals $2 \cdot(1 / 2) U_{\mathrm{s}}$; see Fig. 4a. Therefore, $e m f^{\mathrm{s}} \mathrm{vs} \mathrm{Li} / \mathrm{Li}^{+}$is given by

$$
\begin{aligned}
e m f^{\mathrm{s}} & =-\frac{\mu_{\mathrm{Li}}^{\mathrm{s}}-\mu_{\mathrm{Li}}^{0}}{F}=-\frac{\mu_{\mathrm{Li}}^{\mathrm{n}}+U_{\mathrm{s}}-\mu_{\mathrm{Li}}^{0}}{F} \\
& =-\frac{\Delta G_{\mathrm{chem}}+U_{\mathrm{s}}}{F}=e m f^{\mathrm{n}}-\Delta E_{\mathrm{s}},
\end{aligned}
$$

where $-\Delta E_{\mathrm{s}} \equiv-U_{\mathrm{s}} / F(<0)$ becomes the potential drop.

From the emf value ( $\sim 0.39 \mathrm{~V}$ in Fig. 3$)$ and previous studies on the Al-Li system, ${ }^{9-12}$ the Gibbs energy of AlLi formation (per 1 mole of $\mathrm{Al}), \Delta G_{\text {chem }}$, can be estimated to be about $-38 \mathrm{~kJ} / \mathrm{mol}$. With the use of Eq. (1), the elastic-strain energy $U_{\mathrm{s}}$ caused by AlLi formation can be calculated to be about $67 \mathrm{~kJ} / \mathrm{mol}$ (per 1 mole of $\mathrm{Al}$ ), which is much greater than $9.6 \mathrm{~kJ} / \mathrm{mol}$ for $\mathrm{Sn}_{5} \mathrm{Li}_{2}$ formation. Incidentally, while the
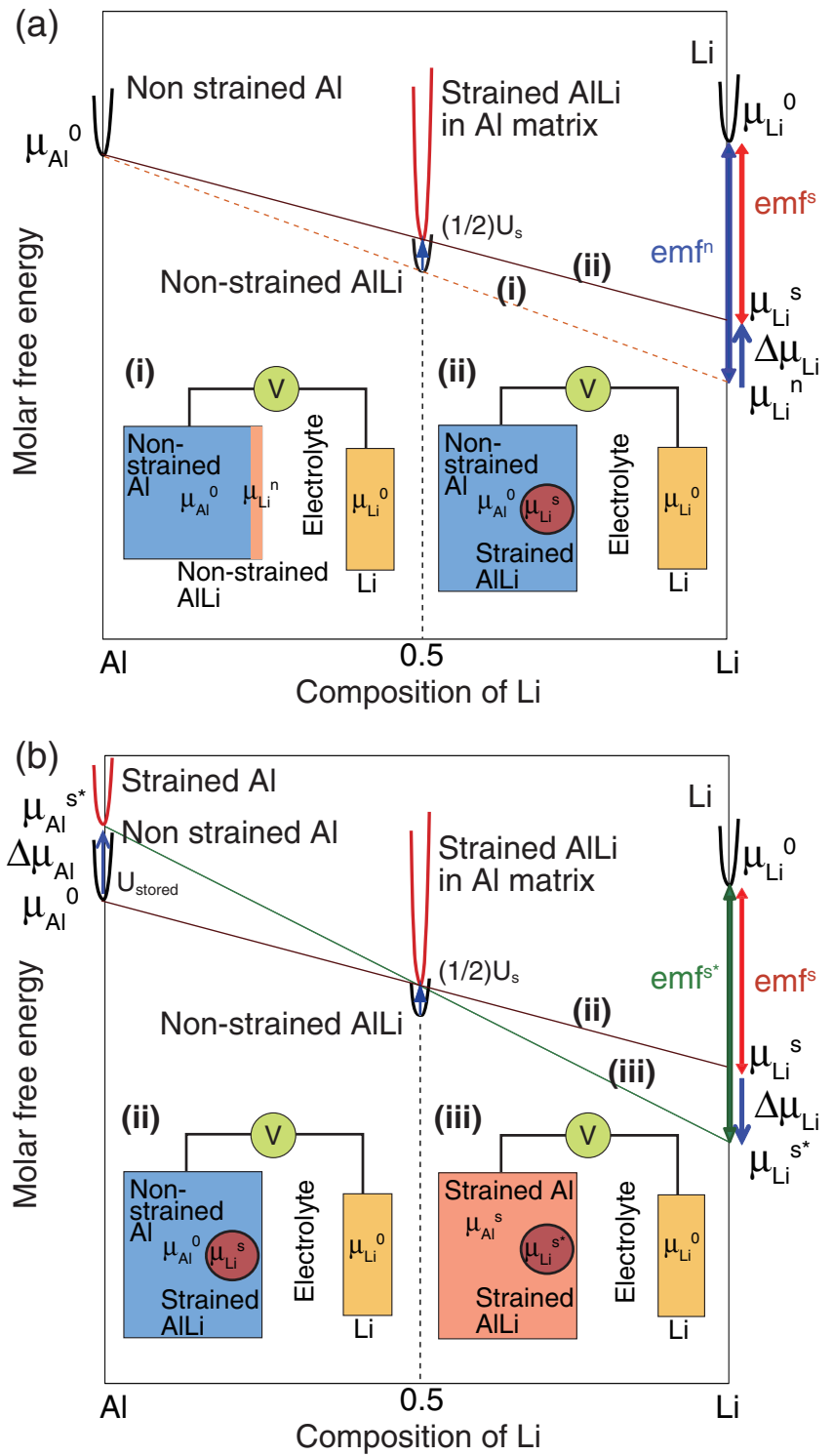

Figure 4. Schematic chemical-potential diagrams to explain the change in the $\mathrm{Li}$ potential when (a) AlLi is formed under an elastic constraint and is in equilibrium with a non-strained $\mathrm{Al}$ matrix, and (b) AlLi is formed under an elastic constraint and is in equilibrium with a strained $\mathrm{Al}$ matrix with a certain stored energy. The inset figures (i)-(iii) correspond to the respective lines indicated by (i)-(iii). Note that case (ii) in (a) is the same as (ii) in (b).

hydrostatic pressure in this case is calculated to be about $18 \mathrm{GPa}$, as noted for the X-ray diffraction profiles, most of the elastic strain is released when the AlLi compound is formed in the Al matrix. For the formation of $\mathrm{Sn}_{5} \mathrm{Li}_{2}, \Delta G_{\text {total }}=\Delta G_{\text {chem }}+U_{\mathrm{s}}<0,{ }^{14}$ whereas $\Delta G_{\text {total }}$ for AlLi formation is positive, so that emf would be negative. Thus, the AlLi compound cannot be formed thermodynamically, unless AlLi is accommodated within the Al matrix by deforming it, which would result in natural degradation of the electrode. This fact is very significant when judging whether or not $\mathrm{Al}$ metal is suitable for use as a negative electrode.

The minimum voltage in the lithiation process in Fig. 1a can be understood as partial destruction of the Al matrix and the relaxation of AlLi in the destroyed matrix. With the insertion of Li ions, AlLi is formed gradually through destruction of the Al matrix. Consequently, the kinetics of lithiation are significantly retarded and the OCV value gradually increases with RT from a quite small value; note that this 
problem is not related to the diffusion rate of $\mathrm{Li}$ in $\mathrm{Al}$. Thus, $\mathrm{Al}$ metal can not be used as a stable negative electrode in a $\mathrm{Li}$ ion battery.

Next, we consider the case where the $\mathrm{Al}$ electrode is strained in advance and stores elastic-strain energy due to the extra dislocations and extra energy as a result of the introduction of extra interfaces by rolling. Here, this energy is simply called "stored energy." According to Fig. 4b, the main difference compared to the above case is that the chemical potential of $\mathrm{Al}$ is higher than the normal value due to the stored energy. In this case, it is very helpful to use the Gibbs-Duhem relation,

$$
x_{\mathrm{Al}} \Delta \mu_{\mathrm{Al}}+x_{\mathrm{Li}} \Delta \mu_{\mathrm{Li}}=0,
$$

where $x_{\mathrm{Al}}=x_{\mathrm{Li}}=0.5$ when considering $\mathrm{Al} / \mathrm{AlLi}$ equilibrium. We discuss here a somewhat complicated case where the pre-strained $\mathrm{Al}$ matrix is in equilibrium with AlLi with a certain strain formed in the crept/partially-destroyed Al matrix, but even this situation can be easily understood with the aid of Fig. 4b.

When the chemical potential of the strained Al matrix is expressed as $\mu_{\mathrm{Al}}^{\mathrm{s} *}$, the change in chemical potential of $\mathrm{Al}$ is given by $\Delta \mu_{\mathrm{Al}}=\mu_{\mathrm{Al}}^{\mathrm{s} *}-\mu_{\mathrm{Al}}^{0} \equiv U_{\text {stored }}(>0)$. Therefore, based on the GibbsDuhem equation, we obtain the important relation,

$$
\mu_{\mathrm{Li}}^{\mathrm{s} *}-\mu_{\mathrm{Li}}^{s}=\Delta \mu_{\mathrm{Li}}=-\Delta \mu_{\mathrm{Al}}=-U_{\text {stored }} .
$$

Since the strain energy $U_{\mathrm{s}}$ with the formation of AlLi is substantially unchanged in both matrices (non-strained $\mathrm{Al}$ and strained $\mathrm{Al}$ ), from Eq. (7) $\Delta G_{\text {chem }}+U_{\mathrm{s}}=\mu_{\mathrm{Li}}^{\mathrm{s}}-\mu_{\mathrm{Li}}^{0}$ holds. After all, emf $\mathrm{s}^{\mathrm{s} *}$ is given by

$$
\begin{aligned}
e m f^{\mathrm{s} *} & =-\frac{\mu_{\mathrm{Li}}^{\mathrm{s} *}-\mu_{\mathrm{Li}}^{0}}{F}=-\frac{\mu_{\mathrm{Li}}^{\mathrm{s}}-U_{\text {stored }}-\mu_{\mathrm{Li}}^{0}}{F} \\
& =-\frac{\Delta G_{\text {chem }}+U_{\mathrm{s}}-U_{\text {stored }}}{F}=e m f^{\mathrm{s}}+\Delta E_{\text {stored }} .
\end{aligned}
$$

Hence $\Delta E_{\text {stored }}=e m f^{s *}-e m f^{s}=U_{\text {stored }} / F(>0)$. Thus, in principle, the stored energy can be evaluated by this methodology. Although we could not provide a quantitative discussion of $\Delta E_{\text {stored }}=e m f^{\mathrm{s} *}$ - emf $f^{\mathrm{s}}$, since none of the OCV values reached equilibrium (they continued to increase gradually even after a rest time of up to $250 \mathrm{~h}$ ), we can see in Fig. 3 that the OCV values tend to be higher with a greater degree of rolling.

\section{Conclusions}

By using a simple Li-Al battery system, we examined why an $\mathrm{Al}$ metal electrode cannot be used in LIB or LB systems even though it has a great advantage from the viewpoint of chemical thermodynamics. For an $\mathrm{Al}$ electrode, the elastic-strain energy associated with AlLi formation is too large to avoid deformation of the Al matrix. Due to this strain effect, the lithiation kinetics are significantly affected and retarded, since lithium insertion and compound formation require thorough destruction of the $\mathrm{Al}$ matrix. In addition, even when the Al matrix already has stored energy, we can discuss the effects of the strain energy and the approach we use may be a unique way to evaluate stored energy other than by a thermal analysis such as with differential scanning spectroscopy. The chemical potential diagram and Gibbs-Duhem relation are very useful for understanding and analyzing electrochemical phenomena under strain.

While we have discussed the case of bulk electrode material, metallic and intermetallic electrodes are actually being considered for use in LIB or LB primarily in a nanostructured form to accommodate volume expansion; in that case, the strain effect would presumably be greatly less than that for bulk material, as shown in the case of Sn nanostructured film. ${ }^{14}$ However, when we consider large battery systems, this strain effect should be more significant. For simplicity, we addressed here only inclusions in the bulk of the host Al. If AlLi is nucleated at the surface in the initial lithiation stage, then the strain can be partially accommodated by the surface. However, as stated in a previous paper, ${ }^{14}$ as lithiation proceeds deeply into the interior, the strain effect becomes substantial. The internal strain that accompanies $\mathrm{Li}$ insertion may also be relevant for conversion reactions that occur, for example, for metal oxides or InSb.

\section{Acknowledgments}

The authors are indebted to Prof. N. Tsuji and Dr. D. Terada of Kyoto University for providing rolled Al samples. T.I. thanks Emeritus Professor Y. Awakura of Kyoto University for fruitful discussions. This work was supported by the New Energy and Industrial Technology Development Organization (NEDO) under the Research \& Development Initiative for Scientific Innovation of New Generation Batteries (RISING).

\section{References}

1. J. B. Goodenough and Y. S. Kim, Chem. Mater. 22, 587 (2010).

2. B. L. Ellis, K. T. Lee, and L. F. Nazar, Chem. Mater. 22, 691 (2010).

3. L. Y. Beaulieu, D. Larcher, R. A. Dunlap, and J. R. Dahn, J. Electrochem. Soc. 147, 3206 (2000).

4. R. A. Huggins, J. Power Sources 81-82, 13 (1999)

5. J. Wang, I. D. Raistrick, and R. A. Huggins, J. Electrochem. Soc. 133, 457 (1986).

6. O. Mao, R. A. Dunlap, and J. R. Dahn, J. Electrochem. Soc. 146, 405 (1999).

7. I. A. Courtney and J. R. Dahn, J. Electrochem. Soc. 144, 2045 (1997).

8. M. Winter and J. O. Besenhard, Electrochim. Acta 45, 31 (1999).

9. N. P. Yao, L. A. Herédy, and R. C. Saunders, J. Electrochem. Soc. 118, 1039 (1971).

10. C. J. Wen, B. A. Boukamp, R. A. Huggins, and W. Weppner, J. Electrochem. Soc. 126, 2258 (1979).

11. D. Fauteux and R. Koksbang, J. Appl. Electrochem. 23, 1 (1993).

12. B. Hallstedt and O. Kim, Int. J. Mat. Res. (formerly Z. Metallkd.) 98, 961 (2007).

13. K. Hirai, T. Ichitsubo, T. Uda, A. Miyazaki, S. Yagi, and E. Matsubara, Acta Mater. 56, 1539 (2008)

14. T. Ichitsubo, S. Yukitani, K. Hirai, S. Yagi, T. Uda, and E. Matsubara, J. Mater. Chem 21, 2701 (2011)

15. Y. J. Zhu and C. S. Wang, J. Power Sources 196, 1442 (2011).

16. Y. T. Cheng and M. W. Verbrugge, J. Appl. Phys. 104, 083521 (2008).

17. T. Mura, Micromechanics of Defects in Solids, 2nd ed, revised (Martinus Nijhoff Pul, The Hague, 1987).

18. J. D. Eshelby, Proc. R. Soc. A 241, 376 (1957).

19. H. Ledbetter and S. Kim, "Monocrystal elastic constants and derived properties of the cubic and the hexagonal elements: in Handbook of Elastic Properties of Solids, Liquids, and Gases, Vol. 2," Academic, San Diego (2001)

20. Y. Hamon, T. Brousse, F. Jousse, P. Topart, P. Buvat, and D. M. Schleich, J. Powe Sources 97-98, 185 (2001). 